\title{
Functional Consequences of Repeated

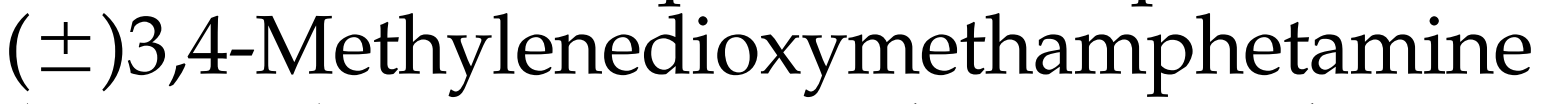 (MDMA) Treatment in Rhesus Monkeys
}

\author{
Michael A. Taffe, Ph.D., Michael R. Weed, Ph.D., Sophia Davis, B.S., \\ Salvador Huitrón-Resendiz, Ph.D., Richard Schroeder, M.S., Loren H. Parsons, Ph.D., \\ Steven J. Henriksen, Ph.D., and Lisa H. Gold, Ph.D.
}

\begin{abstract}
Six rhesus monkeys were trained to stable performance on neuropsychological tests of memory, reinforcer efficacy, reaction time and bimanual motor coordination. Three monkeys were then exposed to a high-dose, short course regimen of $( \pm) 3,4-$ Methylenedioxymethamphetamine (MDMA, "Ecstasy") (4 days, $10 \mathrm{mg} / \mathrm{kg}$ i.m., b.i.d.). Following treatment, concentrations of 5-hydroxyindoleacetic acid (5-HIAA) in cerebrospinal fluid (CSF) were reduced by $\sim 50 \%$ in the treated animals, and this effect persisted for approximately three months post-MDMA. Behavioral performance was disrupted during acute MDMA treatment
\end{abstract}

but returned to baseline within one week following treatment. $M D M A$ also produced persistent alterations in late peak latencies of brainstem auditory evoked potentials (BSAEP), lasting three months post-MDMA. Both CSF 5-HIAA concentrations and evoked potential latencies were normalized four months after treatment. These findings indicate that serotonergic alterations associated with MDMA use may result in persisting changes in brain function.

[Neuropsychopharmacology 24:230-239, 2001] (C) 2001 American College of Neuropsychopharmacology. Published by Elsevier Science Inc.
KEY WORDS: Ecstasy; MDMA; Monkey; Cognition; Memory; Evoked Potential

Recreational use of the psychoactive drug $( \pm) 3,4$,-methylenedioxymethamphetamine (MDMA) has become increasingly popular over the past two decades (Peroutka 1987; Schuster et al. 1998). Although early studies focused on adverse physiological (e.g., hypertension, hyperthermia, hyponatraemia) or psychiatric (mood disorder, aggression) symptoms associated with acute and/or chronic MDMA exposure, recent evidence suggests that chronic MDMA use may also result in lasting

From the Department of Neuropharmacology, The Scripps Research Institute, La Jolla, CA

Address correspondence to: Dr. Michael A. Taffe, Department of Neuropharmacology, CVN-7; The Scripps Research Institute, La Jolla, CA 92037, Tel.: 858-784-7228, E-mail: mtaffe@scripps.edu.

Received March 15, 2000; revised August 1, 2000; accepted August 8, 2000. disruption of cognitive function. A number of studies have shown that experienced, abstinent MDMA users are impaired on various tests of memory function (Bolla et al. 1998; Curran and Travill 1997; Krystal et al. 1992; Morgan 1999; Parrott et al. 1998), even when compared with users of other recreational drugs. The lasting functional effects of MDMA use may be relatively specific to mnemonic processing, since a number of studies have reported that MDMA users who are impaired on memory tasks exhibit normal performance on tests of reaction time, vigilance or selective attention (Krystal et al. 1992; Parrott et al. 1998; Vollenweider et al. 1998). Additional evidence suggests that the degree of memory impairment in the MDMA user is positively correlated with the number of cumulative exposures to MDMA (Bolla et al. 1998; Parrott and Lasky 1998). Finally, recent studies have demonstrated that electroencephalographic and metabolic (PET) measures of brain function are altered in MDMA users (Dafters et al. 1999; Gamma 
et al. 2000; Obrocki et al. 1999). Although the cognitive findings are mostly consistent in the available studies of human MDMA users, the utility of such data is limited by several factors including the subjects' exposure to other drugs of abuse, lack of controlled exposure to MDMA and the difficulty of assessing subtle brain pathology in living human subjects. There is, however, a good deal of evidence derived from animal studies which suggests that MDMA can have adverse effects on central nervous system (CNS) serotonin (5-HT) neurons.

Numerous experiments have demonstrated that MDMA can, under the appropriate dosing regimen, produce lasting alterations in CNS serotonergic systems of both rodents and primates (for review see McKenna and Peroutka (1990) and Steele et al. (1994)). The administration of MDMA twice per day for four days to either Old World or New World monkeys has been shown in several studies to result in depletion of a number of markers for central 5-HT function. Antemortem observations include decreased concentrations of the 5-HT metabolite 5-hydroxyindoleacetic acid (5HIAA) in CSF (Insel et al. 1989; Ricaurte et al. 1988a) and in reduced binding of radio-ligands to the 5-HT transporter in PET studies (Scheffel et al. 1998). Postmortem evidence has shown that the treatment regimen reduces 5-HT and 5-HIAA tissue concentrations, and reduces markers for 5-HT terminals and axons, in a number of brain regions (Ali et al. 1993; Insel et al. 1989; Ricaurte et al. 1988c). In all studies, markers for both dopaminergic and noradrenergic systems remain unchanged following MDMA exposure, indicating that the effect is specific to 5-HT neurons. The CNS effects of MDMA in primates appear to be more profound than in rodents and may not exhibit the same degree of recovery over time (Fischer et al. 1995). The 5-HT alterations are persistent and possibly permanent in nonhuman primates, as the reduction in various markers for central 5-HT function have been observed in squirrel monkeys as long as seven years after the drug regimen (Hatzidimitriou et al. 1999).

Additional studies have suggested that human users of MDMA may also show evidence of 5-HT neuropathology. Much as with MDMA-treated monkeys, there is evidence that CSF concentrations of the 5-HT metabolite 5-HIAA, and 5-HT transporter binding, are decreased in abstinent human MDMA users (Bolla et al. 1998; McCann et al. 1994; Semple et al. 1999). Similarly, in a recent PET study McCann and colleagues (McCann et al. 1998) found that abstinent human MDMA users exhibit reductions in CNS 5-HT transporter binding similar to those of MDMA treated baboons (Scheffel et al. 1998). While such evidence is limited at present it is reasonable to expect that human MDMA users are at risk for the same persistent alteration of 5-HT terminals and axons observed in nonhuman primates, given the similarities between the available human data and those derived from nonhuman primate studies in which the neuropathology is well studied. While the link between 5-HT neuropathology and cognitive disturbance in MDMA users has not been well-established, there is reason to believe that alteration of 5-HT circuits can result in memory or other cognitive disturbances. The temporary experimental depletion of central 5-HT, achieved by administering a mixture of essential amino acids that is deficient in tryptophan, has been shown to impair learning and memory in humans (Park et al. 1994). Furthermore, the 5-HT terminal and axon loss in monkeys treated with MDMA has been shown to be particularly pronounced in brain areas such as the hippocampus, frontal cortex and thalamus (Ali et al. 1993; Insel et al. 1989; Ricaurte et al. 1988c), all of which have been associated with memory performance. It is therefore reasonable to hypothesize that the cognitive disturbances observed in human MDMA users may be related to degeneration of central 5-HT terminals and axons.

Few functional measures, cognitive or otherwise, have been reported in nonhuman primate studies in which alterations in 5-HT markers following repeated treatment with MDMA are well established. In a single study of cognitive/behavioral performance following a repeated, high-dose MDMA regimen in which a 5-HT lesion was produced, Frederick and colleagues (Frederick et al. 1998) found no long term alterations in performance on a number of behavioral tasks. Frederick and Paule (Frederick et al. 1995) have also reported an absence of behavioral changes associated with repeated MDMA, although the escalating dose schedule used in the study did not result in dramatic alterations in central 5-HT markers. This relative paucity of information, combined with the reports of impaired cognition in human users, recommends further examination of the cognitive and functional consequences of the 5-HT alterations produced by a high-dose, short course regimen of MDMA in nonhuman primates.

The present study examined the cognitive, behavioral and electrophysiological effects of repeated, high-dose exposure to MDMA in rhesus monkeys. Monkeys were trained on a battery of several tasks including tests of short-term recognition memory (delayed non-matching to sample; DNMS) and short-term spatial memory (selfordered spatial search; SOSS). A third test of the battery was designed to evaluate alterations of vigilance and reaction time (RT) and tests of fine motor coordination (Bimanual motor) and reinforcer efficacy (progressive ratio; PR) were included as well. Monkeys were trained to perform all tasks concurrently at a stable level of performance (see Weed et al. (1999) for background) to provide a baseline against which to observe treatment effects. In addition to the behavioral tests, non-operant measures of brain function were also included. Sensory evoked potentials (brainstem auditory evoked potentials, 
BSAEP; visual evoked potentials, VEP; cortical auditory evoked potentials, AEP) were recorded on a periodic basis preceding and following the treatment regimen. Finally, CSF was sampled on a periodic basis to evaluate 5-HIAA content, which can be used as an indicator of MDMA-related central 5-HT damage in the intact animal (Ricaurte et al. 1988b).

Study of the functional outcome of repeated MDMA in monkeys serves a number of complementary goals. First, it directly examines the effect of MDMA-induced neurochemical changes on memory, which will help to evaluate reports of memory dysfunction in human users. Second, these studies will provide information regarding the types of cognitive behavior that may require 5-HT mechanisms in primates. Finally, the results may help to identify candidate non-invasive diagnostic tools for early identification of functional impairment related to central 5-HT systems in human MDMA users and other populations.

\section{MATERIALS AND METHODS}

\section{Subjects}

Six adult male rhesus monkeys (Macacca mulatta) served as subjects. The monkeys were approximately five years of age and weighed $5.5-7.5 \mathrm{~kg}$ at the beginning of the study. Animals were individually housed and fed in the home cage after completion of the daily testing session. The animals' normal diet (Lab Diet 5045, PMI Nutrition International) was supplemented with fruit or vegetables four days per week and water was available ad libitum in the home cage at all times. Principles of laboratory animal care (Guide for the Care and use of Laboratory Animals, National Academy Press, 1996) were followed, and all protocols were approved by the Institutional Animal Care and Use Committee of The Scripps Research Institute. The monkeys had extensive training on all components of the behavioral test battery and had received acute doses of scopolamine and amphetamine in studies conducted at least five months prior to receiving MDMA.

\section{Behavioral Testing}

Cognitive and behavioral performance was evaluated using a battery of tests designed for neuropsychological testing of rhesus monkeys which has been previously described (Weed et al. 1999). The battery included tests of memory (delayed non-match to sample; DNMS, selfordered spatial search; SOSS), sustained attention and reinforcer efficacy (progressive ratio; PR), reaction time (RT) and bimanual motor coordination (Bimanual). Performance on tests of this battery has been shown to be differentially sensitive to acute drug manipulation (Taffe et al. 1999; Weed and Gold 1998). Animals were tested five days per week throughout the course of the study, with three tasks being completed each day (i.e., DNMS/RT/Bimanual alternated with PR/SOSS/Bimanual). Testing was conducted approximately 3-5 hours following the morning injection during the treatment week.

Apparatus. Animals were transferred to the testing room in transport cages similar to the home cage but modified by the removal of several bar sections from the front to allow the animal to easily reach out of the cage. The transport cage was placed in front of a computer monitor fitted with a touch-sensitive screen on which stimuli were presented. The animal was trained to reach out of the cage to touch the location on the screen at which visual stimuli were presented to obtain a food pellet reward. Stimulus presentation and response detection were controlled by a micro-computer equipped with a version of the Cambridge Neuropsychological Test Automated Battery (CANTAB; CeNeS, Ltd., Cambridge, UK) designed for use with non-human primates. A dispenser delivered $190 \mathrm{mg}$ flavored pellets (P.J. Noyes Co., Lancaster, NH) to a bin mounted on the front of the cage after correct responses. A whitenoise generator was turned on and an investigator stayed in the testing room during each behavioral session.

Test Battery. The test battery employed consists of five behavioral tasks. Four of the tasks are part of the non-human primate CANTAB and require monkeys to respond by touching the touch-sensitive computer screen and are reinforced with the delivery of food pellet reinforcers. The fifth task requires the animal to extract raisins from holes in a transparent plastic board.

Delayed Non-Matching to Sample (DNMS). The DNMS task is a recognition memory task involving sets of visual discriminations. A sample stimulus is presented in the center of the screen and the animal must make an observing touch to its location within 30 seconds. After a touch, the screen is blanked and following a variable retention interval $(0,16,32$ or $64 \mathrm{sec})$ two choice stimuli are presented in the lower left and right of the screen. One stimulus is identical to the sample stimulus and the other is novel. A touch directed to the novel, or nonmatching stimulus, is followed by reinforcer delivery. In addition to the four retention interval conditions, a simultaneous condition is included in which the sample stimulus remains present after the observing touch and while the choice stimuli are presented. A session consists of 10 trials of each retention interval and the simultaneous condition presented in randomly intermixed fashion for a total of 50 trials. Performance accuracy is measured as a proportion of correct responses to all responses (i.e., errors of omission are excluded from the accuracy calculation). The software utilizes 469 shapes 
and 7 colors to ensure that discriminations are unique for approximately 120,000 trials.

Self-Ordered Spatial Search (SOSS). In each trial of the SOSS task, two, three or four small colored rectangles (boxes) are displayed on the screen in positions randomly allocated from 16 possible locations. The animal must touch a box within 30 seconds of stimulus onset. After each successful touch, the color of the touched box is briefly (100 ms) changed and then the screen is blanked and a reinforcer is delivered. After a 2-second delay, the boxes are re-displayed and the animal must touch a box which has not previously been touched in the trial. The trial is completed when the animal has either touched all boxes without a repetition (correct), touched a box that had previously been selected in that trial (error) or failed to touch a box within 30 seconds of stimulus presentation (omission). Errors and omissions are followed by a tone and a 4-second screen blank. After an inter-trial interval of 5 seconds, another trial is presented with stimuli in new (randomly allocated) positions. A session consists of 40 trials grouped into 6 blocks by trial type as follows: 5 ( 2 boxes), 7 ( 3 boxes), 7 ( 4 boxes), 8 ( 3 boxes), 8 ( 4 boxes), 5 ( 2 boxes). Accuracy scores are calculated for each trial type by dividing the number of correctly completed trials by the number of trials in which there was at least one response (i.e., errors of omission are excluded from the calculation).

Reaction Time. This RT task is a subject-initiated reaction time task which has been shown to be sensitive to the acute administration of dopaminergic drugs (Weed and Gold 1998). For this task a response lever (BRS/LVE, Laurel, MD) is mounted below the monitor and in front of the transport cage. In each trial, a grid of five circles, or target locations, connected by lines is presented in white on the screen. The monkey initiates the trial by holding down the lever. After a pseudorandomly-variable delay lasting between 0.75 and 2.5 seconds, a yellow circle appears within one of the five target locations and is removed after 20,100 or $1000 \mathrm{msec}$. Touching the appropriate circle within 2 seconds (limited hold) results in reinforcer delivery. The time required for the monkey to release the lever (release latency) as well as the time required to touch the circle (response latency) is recorded in milliseconds. The time required to move from lever to target (movement time) is calculated by subtracting the release latency from the response latency.

Progressive-Ratio (PR) Schedule of Responding. In the PR task a large colored rectangle is presented in the center of the screen and the animal must touch the rectangle for reinforcer delivery. The response requirement starts at 1 and increments by arithmetic progression within blocks of 8 reinforcers and by geometric progression between blocks of 8 . (i.e., the first successive 8 ratios increase by 1 , the second successive 8 increase by 2 , the third successive 8 increase by 4 , etc.) The session is terminated after 10 minutes, or earlier if 3 minutes has elapsed since the previous response. In either case, the last completed response ratio and the number of reinforcers earned are recorded.

Bimanual Motor Task (Bimanual). A transparent plastic board drilled with 15 holes is filled with raisins and mounted perpendicular to the door of the transport cage. The hole diameter is such that for efficient retrieval of raisins, the animal must push the raisin partially out of the hole with one finger before retrieving it. With training, animals universally adopt a strategy of pushing the raisin with one hand while retrieving it with the other hand, thus entailing bimanual dexterity. The time required to retrieve all 15 raisins is recorded by stopwatch.

\section{Drug and Dosing}

Three monkeys were treated with $10 \mathrm{mg} / \mathrm{kg}( \pm) 3,4$,methylenedioxymethamphetamine $\mathrm{HCl}$ (MDMA) twice daily (at 6:15 am and 6:15 pm) for four days. The three remaining animals served as controls and were injected with saline on the same schedule. MDMA was dissolved in sterile saline and injected (i.m.) on a $0.1 \mathrm{ml} / \mathrm{kg}$ basis. MDMA was obtained from the National Institute on Drug Abuse.

\section{Electrophysiological Recording}

Evoked potentials (brainstem auditory evoked potentials, BSAEP; cortical auditory evoked potentials, AEP; and visual evoked potentials, VEP) were recorded under ketamine anaesthesia (20 mg/ kg, i.m.) 2, 4, 9, 13, and 17 weeks after cessation of MDMA treatment. Pre-treatment baseline recordings were obtained on three occasions separated by no less than four weeks. The procedure has been detailed previously (Prospero-Garcia et al. 1996). In brief, electrodes were placed subcutaneously at the cranial vertex (active), over the greater alar cartilage (reference) and in the musculature of the neck (ground). Raw electroencephalographic signals (EEG) were amplified and filtered within a bandwidth of 30$3000 \mathrm{~Hz}$ for BSAEP and 1-100 Hz for AEPs and VEPs. Binaural condensation stimulation, produced by clicks generated by $0.10 \mathrm{~ms}$ square waves and delivered at a $70 \mathrm{~dB}$ sound pressure level at a rate of $10 \mathrm{~Hz}$, was used to generate BSAEPs. A frequency of $1 \mathrm{~Hz}$ was used to generate AEPs. Visual stimulation was delivered binocularly in flashes of $0.1 \mathrm{~ms}$ duration with a lamp placed 10 $\mathrm{cm}$ from the nose of the monkey. Ambient lights remained on throughout. BSAEPs were calculated by averaging the first $10 \mathrm{~ms}$ of EEGs recorded for 1024 samples. AEPs and VEPs were calculated by averaging the first $200 \mathrm{~ms}$ of EEGs recorded for 100 samples. Several component 
peaks are identified in the average waveform for individual BSAEPs (P1, P2a, P2b, P3, P4, P5), VEPs (P1, N1, P2a, $\mathrm{P} 2 b, \mathrm{~N} 2)$ and AEPs (P1, N1a, P2a, N1b, P2b, N2). Latencies were not corrected for the delay introduced due to the length of tubing connecting the speaker to the ear canals.

\section{CSF Analysis}

CSF (1-2 ml) was collected by percutaneous cisternal puncture using aseptic techniques under ketamine anesthesia $(20 \mathrm{mg} / \mathrm{kg})$. Pre-treatment samples were collected 2, 3 and 4 months prior to MDMA treatment and additional samples were collected 2, 4, 9, 13, 17 and 21 weeks after the MDMA regimen. Samples were centrifuged to remove cellular contamination and stored at $-70^{\circ} \mathrm{C}$. CSF concentrations of monoamine metabolites were measured by high-performance liquid chromatography with electrochemical detection. For analysis, 20 $\mu l$ of $0.1 \mathrm{~N}$ perchloric acid was added to $180 \mu \mathrm{l}$ of CSF and the sample was incubated on ice for 30 minutes. Samples $(100 \mu \mathrm{l})$ were then injected into a $300 \mathrm{~mm} \times 3.9$ $\mathrm{mm}, \mathrm{C}_{18}$ reverse phase column (Waters Resolve) with a mobile phase consisting of $0.166 \mathrm{M}$ citric acid, $25 \mathrm{mM}$ Na acetate, $0.1 \mathrm{mM}$ EDTA, $4 \mathrm{ml} / 1$ TEA, $0.9 \mathrm{mM}$ SOS and $10 \%$ methanol, $\mathrm{pH} 2.5$.

\section{Data Analysis}

All data was analyzed by repeated-measures analysis of variance (ANOVA) with a between-subjects factor of treatment group. The Greenhouse-Geisser adjustment was made to the probability value when necessary. For the CSF (5-HIAA, HVA; \% of pre-treatment average) and electrophysiological (peak latency; msec) parameters, planned contrasts were used to compare each time point following MDMA (or saline) treatment with the average of three pre-treatment observations for each group of animals. The group mean was substituted for missing CSF samples on three occasions (no more than one per analysis cell). In addition, planned contrasts were used to compare the MDMA-treated group to the saline-treated group at each timepoint. Behavioral data were averaged across the several sessions run for each task (e.g., 2-3 weekly) in the time prior to each periodic electrophysiological recording and CSF tap. Pre-treatment comparison data were derived from sessions run in the four weeks preceding MDMA treatment. The data analyzed for the behavioral tasks were: \% correct trials (SOSS); \% correct choices (DNMS); \# of reinforcers obtained (PR); \% of pre-treatment latency (RT); and time to completion (Biman). Significant main effects for the behavioral tasks were followed by post hoc comparisons conducted using the Tukey-Kramer procedure. A significance criterion of $p<.05$ was used for all ANOVA, planned contrasts and post hoc tests.

\section{RESULTS}

\section{CSF Monoamine Metabolites}

The average pretreatment CSF 5-HIAA concentrations for the MDMA-treated and control groups were 182 (sd = $90)$ and $183(\mathrm{sd}=56) \mathrm{nM}$, respectively. The MDMA regimen resulted in a $44 \%$ reduction in 5-HIAA concentrations as is shown in Figure 1. Statistical analysis confirmed a significant main effect of treatment group $\left[\mathrm{F}_{1,4}=\right.$ $16.106, p<.05]$, CSF sample date $\left[\mathrm{F}_{8,27}=3.971, p<.05\right]$ and an effect of the interaction between the two factors $\left[\mathrm{F}_{8,27}=2.217, p<.05\right]$ on CSF 5-HIAA. Planned contrasts confirmed that these effects were attributable to a posttreatment reduction in 5-HIAA content observed in the MDMA group as there was a significant difference between the average of three pre-treatment observations and each post-treatment mean collected between 2 and 17
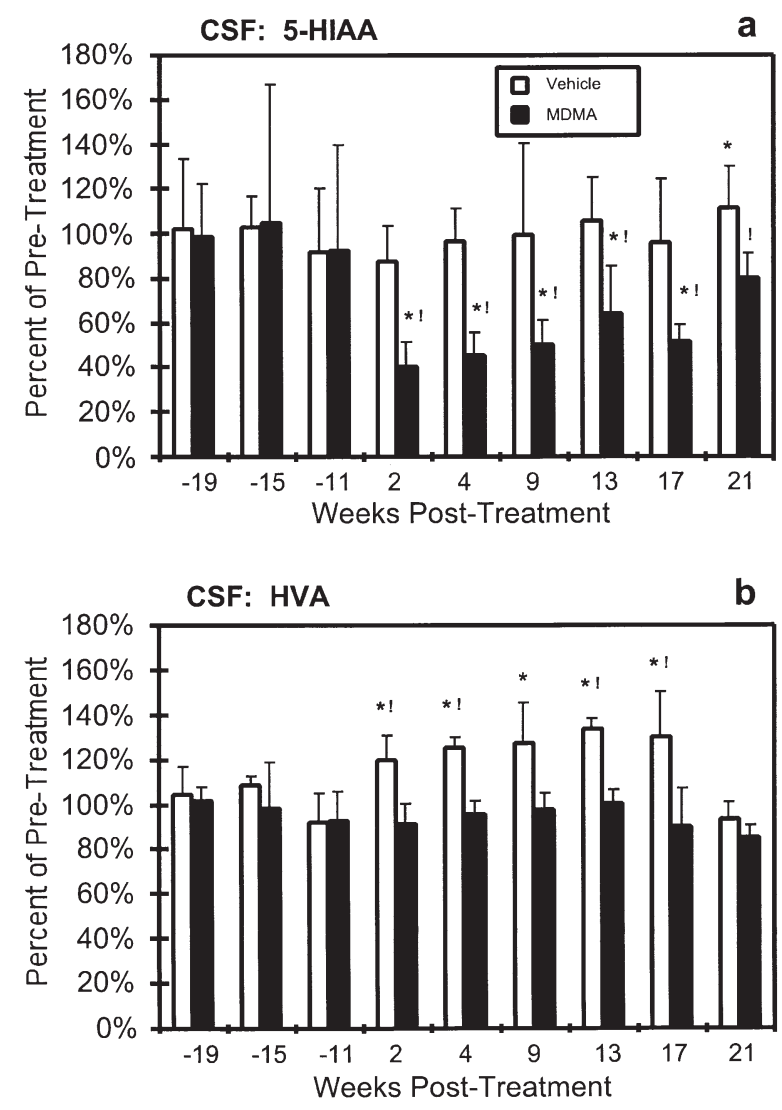

Figure 1. Mean ( \pm SEM) concentrations of 5-HIAA (Panel a) and HVA (Panel b) in the CSF of MDMA-treated $(n=3)$ and vehicle-treated $(n=3)$ monkeys sampled at timepoints prior to, and following, the treatment week. The data are expressed as a proportion of pre-treatment mean concentrations for each subject. The MDMA treatment regimen reduced 5-HIAA concentrations by approximately 50\% compared with either control or pre-treatment means. A significant difference $(p<.05)$ from the pre-treatment average within a group is indicated by * and a significant difference between groups at a given time point is indicated by !. 
weeks following MDMA treatment. The effect is likely to be specific to the MDMA regimen, since in the control group, while 5-HIAA concentrations were significantly higher than the pre-treatment average at week 21, no other post-treatment samples differed. Furthermore, planned contrasts confirmed that the mean 5-HIAA levels for the MDMA-treated group were significantly lower than the control group for all time points post-treatment but not for any of the three pre-treatment samples.

The average pretreatment HVA concentrations for the MDMA and control groups were 1159 (sd = 119) and $1205(\mathrm{sd}=126) \mathrm{nM}$. The MDMA regimen reduced HVA concentrations in the CSF relative to control animals but not relative to pre-treatment concentrations, as is shown in Figure 1. There was a significant main effect of treatment group $\left[\mathrm{F}_{1,4}=14.761, p<.05\right]$ and CSF sample date $\left[\mathrm{F}_{8,27}=2.401, p<.05\right]$ (but no significant effect of the interaction $\left[\mathrm{F}_{8,27}=1.524, p>.05\right]$ ) on CSF HVA. These effects were attributable to an elevation of HVA in the CSF of the saline-treated animals from 2 to 17 weeks following the treatment regimen as was confirmed by planned contrasts. HVA concentrations were significantly higher in the saline-treated group compared with pre-treatment values $(2,4,9,13$ and 17 weeks post-treatment) and compared with the MDMAtreated group $(2,4,13$ and 17 weeks post treatment). The HVA concentrations in the MDMA-treated group did not differ significantly from pre-treatment values at any of the six observations following treatment.

\section{Electrophysiology}

The MDMA regimen significantly affected the latency of later components of the BSAEPs and some of these alterations persisted up to 13 weeks following the cessation of MDMA, as is illustrated in Figure 2. Statistical analysis confirmed a significant difference in P3 latency in the treatment group following the drug regimen (Figure 2), reflected in a significant effect of treatment group $\left[\mathrm{F}_{1,4}=8.621, p<.05\right]$ and recording date $\left[\mathrm{F}_{6,24}=\right.$ $4.978, p<.05]$ in the ANOVA. Post-hoc comparison confirmed that P3 latencies recorded two, nine and thirteen weeks following treatment were significantly faster than the pre-treatment mean in the MDMA group but not in the control group. As is shown in Figure 2, mean latency of the P4 peak in the MDMAtreated animals was significantly faster during a three month period following the drug regimen. The ANOVA confirmed significant differences in latency attributable to treatment group $\left[\mathrm{F}_{1,4}=120.334, p<.05\right]$, date of recording $\left[\mathrm{F}_{6,24}=15.622, p<.05\right]$ and the interaction of the two factors $\left[\mathrm{F}_{6,24}=8.135, p<.05\right]$. Post-hoc comparisons confirmed that $\mathrm{P} 4$ latencies recorded up to three months ( $2 \mathrm{wk}, 4 \mathrm{wk}, 9 \mathrm{wk}$ and $13 \mathrm{wk}$ recordings) following treatment were significantly different when compared with either the pre-treatment mean of the

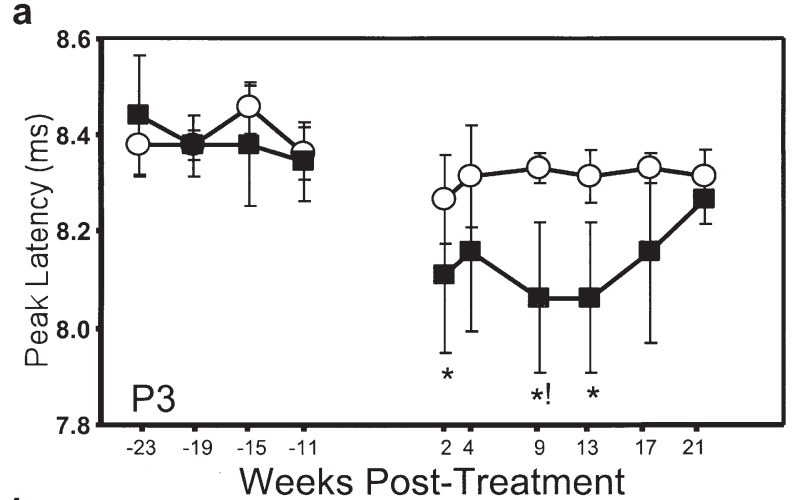

b
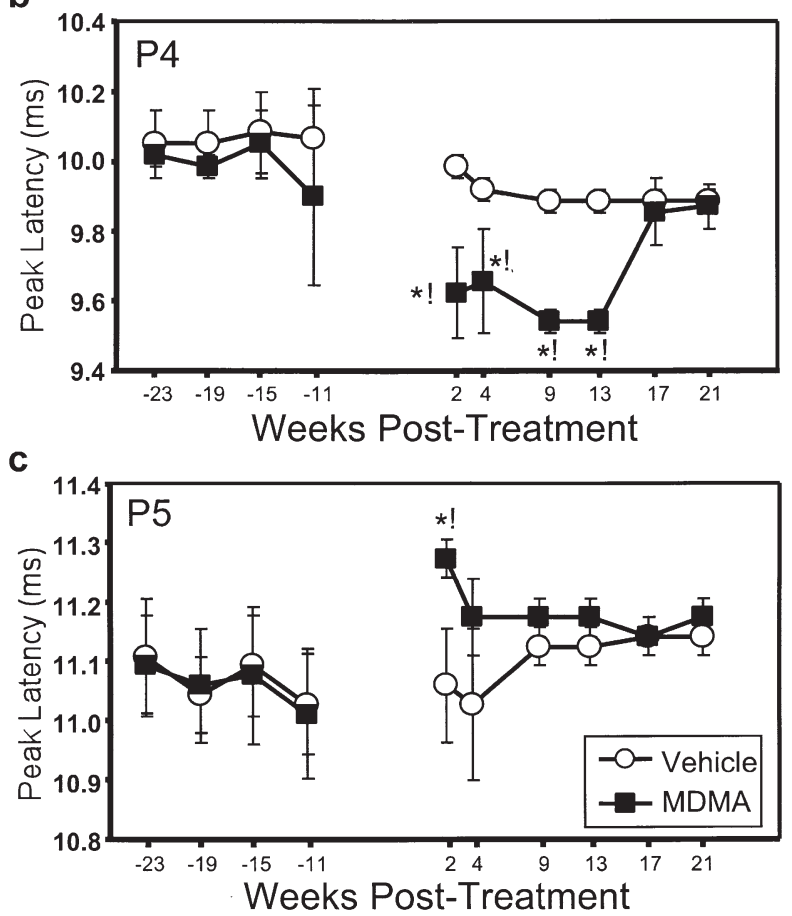

Figure 2. Mean ( \pm SEM) peak latency is plotted for each of three later BSAEP components (P3, P4 and P5) recorded from MDMA-treated $(n=3)$ and vehicle-treated $(n=3)$ groups at timepoints prior to, and following, the treatment week. The MDMA regimen decreased P3 and P4 latencies for approximately 13 weeks following MDMA exposure. A significant difference $(p<.05)$ from the pre-treatment average within a group is indicated by ${ }^{*}$ and a significant difference between groups at a given time point is indicated by!.

treated group or the control group latency recorded at the same time points. As is shown in Figure 2, mean latency of the P5 peak was significantly longer in the MDMAtreated group two weeks following treatment. The ANOVA confirmed significant differences in latency attributable to treatment group $\left[\mathrm{F}_{1,4}=24.909, p<.05\right]$, date of recording $\left[\mathrm{F}_{6,24}=3.040, p<.05\right]$ and the interaction of the two factors $\left[\mathrm{F}_{6,24}=3.68, p<.05\right]$. Post-hoc comparisons confirmed that P5 latency recorded two weeks following treatment was significantly slower compared with both the pre-treatment mean of the treated group 
and the control group latency recorded at the same time. The drug treatment did not significantly affect the latency of any of the earlier BSAEP peaks (P1, P2a, P2b).

There were no significant differences in any peak latencies of VEP or AEP response that were attributable to either treatment group, recording date or the interaction between the two effects.

\section{Behavior}

Behavioral performance means for each group $(\mathrm{N}=3$ per group) are summarized in Table 1. Scores in each task were averaged over multiple sessions (2-3 per week; see METHODS) conducted during time intervals determined by the CSF tap and electrophysiological recording schedule. The pre-treatment data are derived from sessions conducted in the four weeks immediately prior to the MDMA (or vehicle) treatment week. Release latencies and movement times in the RT task were expressed as a proportion of pre-treatment values for each individual subject. For all tests, errors of omission were excluded from the presentation and the analysis.
The effect of the MDMA treatment regimen was consistent across all behavioral tasks in that performance was impaired during the treatment week in the MDMA-treated animals but not in the vehicle-treated animals. In the subsequent months, the treated animals performance did not differ significantly from pre-treatment levels. The significant decrement in SOSS performance observed in the control group 4-5 months following the vehicle treatment regimen was coincident with the introduction of an additional SOSS difficulty condition (five-box trials were added to provide a wider performance range for future studies). Only a single animal's performance (out of the control or MDMA groups) was severely affected and this effect lasted less than two months (individual data not shown). DNMS choice accuracy was consistently less than perfect in the simultaneous condition, an observation that is consistent with all groups of animals trained in the lab on this task (e.g. Taffe et al. (1999); Weed et al. (1999)), as well as the delayed matching to sample variant (unpublished observations). Similarly, there was no significant effect of retention interval on choice accu-

Table 1. Behavioral Performance, Averaged Across Multiple Sessions, During the Weeks Following Repeated Treatment with MDMA or Vehicle

\begin{tabular}{|c|c|c|c|c|c|c|c|c|c|c|}
\hline Task & Group & $\begin{array}{c}\text { Task } \\
\text { Parameter }\end{array}$ & Pre-Treat & $\begin{array}{l}\text { Treatment } \\
\text { Week }\end{array}$ & $\begin{array}{c}\text { Weeks } \\
1-2\end{array}$ & $\begin{array}{c}\text { Weeks } \\
3-4\end{array}$ & $\begin{array}{c}\text { Weeks } \\
5-9\end{array}$ & $\begin{array}{l}\text { Weeks } \\
10-13\end{array}$ & $\begin{array}{l}\text { Weeks } \\
14-17\end{array}$ & $\begin{array}{c}\text { Weeks } \\
18-21\end{array}$ \\
\hline $\begin{array}{l}\text { SOSS } \\
\text { (percent } \\
\text { correct) }\end{array}$ & Control & $\begin{array}{l}2 \text { Box } \\
3 \text { Box } \\
4 \text { Box } \\
2 \text { Box } \\
3 \text { Box } \\
4 \text { Box }\end{array}$ & $\begin{array}{l}98.3 \% \\
94.4 \% \\
82.8 \% 3 \\
99.2 \% \\
92.5 \% \\
81.4 \% 3\end{array}$ & $\begin{array}{l}98.2 \% \\
91.4 \% \\
82.5 \%^{3} \\
\mathbf{7 2 . 4} \%^{1} \\
\mathbf{6 7 . 1} \%^{1} \\
\mathbf{5 3 . 5} \%^{13}\end{array}$ & $\begin{array}{l}99.3 \% \\
89.8 \% \\
80.5 \%{ }^{3} \\
98.0 \% \\
92.0 \% \\
83.8 \%^{3}\end{array}$ & $\begin{array}{l}98.3 \% \\
93.3 \% \\
87.7 \% \\
95.8 \% \\
92.8 \% \\
80.6 \%^{3}\end{array}$ & $\begin{array}{l}98.6 \% \\
96.8 \% \\
89.5 \% \\
98.6 \% \\
93.3 \% \\
84.8 \%^{3}\end{array}$ & $\begin{array}{l}97.9 \% \\
92.2 \% \\
85.3 \%^{3} \\
97.3 \% \\
93.5 \% \\
84.1 \%^{3}\end{array}$ & $\begin{array}{l}98.9 \% \\
92.2 \% \\
\mathbf{6 4 . 4} \% \mathbf{1 3} \\
98.7 \% \\
93.8 \% \\
81.2 \%{ }^{3}\end{array}$ & $\begin{array}{l}\mathbf{8 3 . 3} \%^{1} \\
\mathbf{7 7 . 3} \mathbf{\%}^{\mathbf{1}} \\
77.8 \% \\
98.3 \% \\
93.0 \%^{1} \\
79 . \%^{3}\end{array}$ \\
\hline $\begin{array}{l}\text { DNMS } \\
\text { (percent } \\
\text { correct) }\end{array}$ & Control & $\begin{array}{l}\text { Simultaneous } \\
0 \text { seconds } \\
16 \text { seconds } \\
32 \text { seconds } \\
64 \text { seconds } \\
\text { Simultaneous } \\
0 \text { seconds } \\
16 \text { seconds } \\
32 \text { seconds } \\
64 \text { seconds }\end{array}$ & $\begin{array}{l}91.5 \% \\
93.0 \% \\
92.7 \% \\
82.7 \% \\
82.8 \% \\
93.0 \% \\
94.3 \% \\
93.6 \% \\
89.0 \% \\
89.6 \%\end{array}$ & $\begin{array}{l}96.7 \% \\
89.5 \% \\
96.7 \% \\
80.8 \% \\
74.9 \% \\
75.0 \% \\
\mathbf{7 2 . 8} \%^{1} \\
81.5 \% \\
74.4 \% \\
\mathbf{6 2 . 9} \mathbf{1}^{1}\end{array}$ & $\begin{array}{l}89.2 \% \\
95.0 \% \\
91.8 \% \\
89.0 \% \\
87.8 \% \\
92.1 \% \\
95.6 \% \\
96.6 \% \\
88.8 \% \\
90.4 \%\end{array}$ & $\begin{array}{l}90.6 \% \\
92.8 \% \\
88.8 \% \\
89.6 \% \\
73.4 \%{ }^{4} \\
88.2 \% \\
93.1 \% \\
95.8 \% \\
92.3 \% \\
89.1 \%\end{array}$ & $\begin{array}{l}83.8 \% \\
90.4 \% \\
87.5 \% \\
84.6 \% \\
83.0 \% \\
93.0 \% \\
88.2 \% \\
96.3 \% \\
91.8 \% \\
90.1 \%\end{array}$ & $\begin{array}{l}88.4 \% \\
90.7 \% \\
91.2 \% \\
73.7 \% \\
82.4 \% \\
90.5 \% \\
96.7 \% \\
92.8 \% \\
93.2 \% \\
86.9 \%\end{array}$ & $\begin{array}{l}92.5 \% \\
92.8 \% \\
90.5 \% \\
86.9 \% \\
80.6 \% \\
88.7 \% \\
94.3 \% \\
90.4 \% \\
89.1 \% \\
88.1 \%\end{array}$ & $\begin{array}{l}90.2 \% \\
90.1 \% \\
90.4 \% \\
88.4 \% \\
78.8 \% \\
92.6 \% \\
90.1 \% \\
90.2 \% \\
89.9 \% \\
88.2 \%\end{array}$ \\
\hline $\begin{array}{l}\text { RT } \\
\text { (percent } \\
\text { of pre- } \\
\text { treat) }\end{array}$ & $\begin{array}{l}\text { Control } \\
\text { MDMA }\end{array}$ & $\begin{array}{l}\text { Release } \\
\text { Movement } \\
\text { Release } \\
\text { Movement }\end{array}$ & $\begin{array}{l}100 \% \\
100 \% \\
100 \% \\
100 \%\end{array}$ & $\begin{array}{c}117 \% \\
88 \% \\
\mathbf{1 5 7}^{\mathbf{1}}{ }^{\mathbf{1}} \\
81 \%\end{array}$ & $\begin{array}{r}99 \% \\
110 \% \\
104 \% \\
106 \%\end{array}$ & $\begin{array}{r}112 \% \\
109 \% \\
118 \% \\
90 \%\end{array}$ & $\begin{array}{r}103 \% \\
95 \% \\
96 \%\end{array}$ & $\begin{array}{r}95 \% \\
144 \% \\
87 \% \\
130 \%\end{array}$ & $\begin{array}{r}100 \% \\
124 \% \\
83 \% \\
115 \%\end{array}$ & $\begin{array}{r}118 \% \\
84 \% \\
96 \%\end{array}$ \\
\hline PR & $\begin{array}{l}\text { Control } \\
\text { MDMA }\end{array}$ & $\begin{array}{l}\text { \# of Reinforcers } \\
\text { \# of Reinforcers }\end{array}$ & $\begin{array}{l}20.7 \\
23.4\end{array}$ & $\begin{array}{l}19.0 \\
4.8^{12}\end{array}$ & $\begin{array}{l}15.8 \\
17.9\end{array}$ & $\begin{array}{l}15.5 \\
23.7\end{array}$ & $\begin{array}{l}19.3 \\
22.3\end{array}$ & $\begin{array}{l}17.8 \\
20.8\end{array}$ & $\begin{array}{l}18.0 \\
22.3\end{array}$ & $\begin{array}{l}18.8 \\
20.9\end{array}$ \\
\hline BIMAN & $\begin{array}{l}\text { Control } \\
\text { MDMA }\end{array}$ & $\begin{array}{l}\text { Latency (sec) } \\
\text { Latency (sec) }\end{array}$ & $\begin{array}{l}16.9 \\
17.0\end{array}$ & $\begin{array}{l}17.8 \\
30.3^{12}\end{array}$ & $\begin{array}{l}15.4 \\
18.0\end{array}$ & $\begin{array}{l}16.9 \\
18.6\end{array}$ & $\begin{array}{l}14.9 \\
17.6\end{array}$ & $\begin{array}{l}15.1 \\
17.2\end{array}$ & $\begin{array}{l}16.3 \\
18.4\end{array}$ & $\begin{array}{l}15.4 \\
17.7\end{array}$ \\
\hline
\end{tabular}

Mean performance of the MDMA-treated $(\mathrm{N}=3)$ and the vehicle-treated $(\mathrm{N}=3)$ groups on each of the behavioral tasks is summarized. Data for individual animals were derived from the 2-3 weekly sessions conducted per task within the time periods indicated. The MDMA-treated group's performance on each task was impaired during the treatment week however some delay conditions of DNMS and movement time of the RT task were spared. There were no lasting effects of the drug regimen beyond the treatment week. A significant decrease in Control group SOSS performance in weeks 14-21 is attributable to the addition of a 5-box difficulty condition (see text). ${ }^{1}$ Value differs significantly from pre-treatment value within group $(p<.05) .{ }^{2}$ MDMA-treated group differs significantly from Control group $(p<.05)$. ${ }^{3}$ SOSS- Differs significantly from 2 box condition at same date $(p<$ .05). ${ }^{4}$ DNMS- Differs significantly from 0 second delay condition at same date $(p<.05)$. SOSS, Self-Ordered Spatial Search; DNMS, Delayed NonMatching to Sample; RT, Reaction Time; PR, Progressive Ratio Responding; BIMAN, Bimanual Motor Task. 
racy although there is a clear trend for performance to be slightly worsened at the longer retention intervals. Again, this pattern is consistent with previous observations and illustrates the incomplete homology between monkey and human performance in this version of the matching to sample task. For the present purposes it is clear that MDMA treatment does not have a lasting effect on performance of this task.

\section{DISCUSSION}

In the present results, the high-dose, repeated MDMA regimen produced reductions in CSF concentrations of the 5-HT metabolite 5-HIAA which persisted for at least four months. The magnitude of the initial 5-HIAA reduction $(\sim 40-50 \%)$ was consistent with previous reports in which the analysis of CSF 5-HIAA concentrations was combined with a more exhaustive analysis of the neuroanatomical and neurochemical outcome (Insel et al. 1989; Ricaurte et al. 1988b; Ricaurte et al. 1992). It is therefore probable that the present MDMA-exposed monkeys experienced reductions in tissue 5-HT concentrations and 5-HT terminal markers, consistent with previous studies. The MDMA regimen did not change CSF levels of the DA metabolite HVA in comparison with pre-treatment values, however the levels were significantly lower in comparison with the control group for up to four months following treatment. Therefore the possibility that central dopamine levels were significantly altered after MDMA treatment cannot be definitively excluded, although previous studies have consistently failed to find any alterations in brain dopaminergic function following MDMA treatment (Insel et al. 1989; Ricaurte et al. 1988b; Ricaurte et al. 1992).

Performance on the cognitive/behavioral battery measures was disrupted by acute treatment with MDMA. Animals were particularly impaired on SOSS accuracy, release latency in the RT task, bimanual performance and progressive ratio performance. DNMS choice accuracy was only significantly disrupted at two retention intervals and RT movement time was not significantly altered. There were no apparent lasting effects of the 5-HT alterations produced by MDMA on any of the cognitive/behavioral measures. This finding is consistent with the report of Frederick et al. (Frederick et al. 1998) but extends their findings to additional tests of cognitive performance. Of particular note in the current data was the lack of any detectable long-term effects of the MDMA regimen on memory performance (SOSS and DNMS) since studies in abstinent human MDMA users show a consistent pattern of observed memory deficiency (Bolla et al. 1998; Curran and Travill 1997; Krystal et al. 1992; Morgan 1999; Parrott et al. 1998), although Morgan (1998) found MDMA users to be unimpaired on spatial span. There are a number of possible explanations for this discrepancy between the observations in human MDMA users and MDMAexposed monkeys. It may be the case that the differences in testing procedures (repeated training on the test battery vs. the one-time testing of humans) makes the monkeys' performance more resistant to disruption. Humans may be more sensitive to the 5-HT depleting effects of MDMA or, alternately, human memory may be more dependent on intact 5-HT terminals. Finally, the magnitude of the neuropathology produced by MDMA in the present study may not have been large enough to interfere with memory in any significant way, although the $\sim 25 \%$ reductions in 5-HT markers in studies of human MDMA users relative to controls (Bolla et al. 1998; McCann et al. 1998) suggests that human memory can be affected with 5-HT depletions of a lower magnitude than was observed in the monkeys. In one study where human users were shown to exhibit memory deficits, those deficits were significantly associated with lower CSF 5-HIAA and moderately associated with the estimated monthly MDMA intake (Bolla et al. 1998). These latter observations suggest that MDMA treated monkeys are indeed less sensitive to the cognitive symptoms of 5-HT depletion compared with the chronic MDMA user.

The second major finding of the present study is the fact that MDMA treatment resulted in lasting alterations of the BSAEP response, which has not been reported in either human users or MDMA treated monkeys to date. This important observation suggests that a persisting depletion of central serotonin observed in nonhuman primates following treatment with MDMA can have consequences for at least one aspect of brain function. The persisting decrease in P3 and P4 latency is likely related to disruption of 5-HT projections to specific brainstem auditory nuclei (including the cochlear nucleus, the superior olivary nucleus and the nucleus of the lateral lemniscus) since previous investigations have shown that there is significant 5-HT input to these regions in a number of species (Thompson et al. 1995; Thompson and Thompson 1995; Thompson and Thompson 1986). Thompson and colleagues (Thompson et al. 1994) have proposed, in a review of electrophysiological findings, that such projections play an inhibitory role. These findings are consistent with the present observation of decreased latencies of later BSAEP peaks following MDMA treatment. Unfortunately, little is known regarding the extent of 5-HT alteration in brainstem regions of animals treated with a repeated MDMA regimen since previous studies have focused on foreand mid-brain regions. The available evidence is equivocal since, in the limited number of studies conducted in MDMA-treated rats, both unchanged as well as depleted 5-HT content have been reported in (undifferentiated) brainstem tissue samples (Aguirre et al. 1995; Li et al. 1989; Yeh 1999). The specific effect of MDMA 
treatment on 5-HT innervation of brainstem auditory nuclei has not been reported. The present BSAEP observations support future neuroanatomical evaluation of 5-HT projections to brainstem auditory nuclei following MDMA treatment.

In summary, the present observations suggest that disruption of central 5-HT mechanisms can alter brain function as measured by cognitive or electrophysiological metrics. First, cognitive/behavioral performance was disrupted by acute doses of MDMA during the treatment week, presumably due to an enhancement of 5-HT release. Second, cognitive/behavioral measures were normal whereas brainstem auditory evoked potentials were abnormal for a period of at least three months following MDMA treatment. The persisting effect on BSAEPs is consistent with a loss of 5-HT innervation of brainstem auditory nuclei. The normalization of the cognitive/behavioral measures suggests that these domains may be more sensitive to enhancement than to reduction in central 5-HT transmission. Finally, the normalization of the BSAEP P3 and P4 latencies between 3 and 4 months following MDMA (combined with the recovery of CSF 5-HIAA concentrations) indicates that either 5-HT innervation of the CNS recovers, or alternately, compensation takes place to a sufficient degree to normalize these electrophysiological alterations. It remains to be determined, however, the degree to which recovery occurs and whether repeated cycles of 5-HT insult combined with incomplete recovery or compensation (such as might be experienced in chronic human use) pose cumulative liability. The present findings also suggest that MDMA-induced compromise of brain function may be most pronounced in auditory pathways. Therefore proposals that MDMA does not affect early information processing or selective attention (Parrott et al. 1998; Vollenweider et al. 1998) may be premature as such studies used tests that rely on the visual domain. Tests of vigilance or selective attention that are conducted in the auditory domain may well show alterations in MDMA users. It is also suggestive that studies which failed to find memory impairment in human MDMA users employed non-auditory tasks (Morgan 1998) whereas studies which did find evidence of specific memory impairment used at least one auditory memory task (Bolla et al. 1998; Morgan 1999). Ultimately, the present results present the possibility that BSAEP peak latencies may be utilized as a sensitive diagnostic of MDMA-associated changes in the human MDMA user and recommend that traditional neuropsychological evaluation incorporate tests of auditory processing.

\section{ACKNOWLEDGMENTS}

Supported by USPHS grants: MH19185 (MAT), DA05831 (MRW), DA11004 (LHP), MH47680 (SJH, SH-R) and DA09111
(LHG). This is publication \#13142-NP from The Scripps Research Institute.

\section{REFERENCES}

Aguirre N, Galbete JL, Lasheras B, Del Rio J (1995): Methylenedioxymethamphetamine induces opposite changes in central pre- and post-synaptic 5-HT1A receptors in rats. Eur J Pharmacol 281:101-105

Ali SF, Newport GD, Scallet AC, Binienda Z, Ferguson SA, Bailey JR, Paule MG, Slikker W, Jr. (1993): Oral administration of 3,4-methylenedioxymethamphetamine (MDMA) produces selective serotonergic depletion in the nonhuman primate. Neurotoxicol Teratol 15:91-96

Bolla KI, McCann UD, Ricaurte GA (1998): Memory impairment in abstinent MDMA ("Ecstasy") users. Neurology 51:1532-1537

Curran HV, Travill RA (1997): Mood and cognitive effects of +/-3,4-methylenedioxymethamphetamine (MDMA, 'ecstasy'): week-end 'high' followed by mid-week low. Addiction 92:821-831

Dafters RI, Duffy F, O’Donnell PJ, Bouquet C (1999): Level of use of 3,4-methylenedioxymethamphetamine (MDMA or Ecstasy) in humans correlates with EEG power and coherence. Psychopharmacology (Berl) 145:82-90

Fischer C, Hatzidimitriou G, Wlos J, Katz J, Ricaurte G (1995): Reorganization of ascending 5-HT axon projections in animals previously exposed to the recreational drug (+/-)3,4methylenedioxymethamphetamine (MDMA, "ecstasy"). J Neurosci 15:5476-5485

Frederick DL, Ali SF, Gillam MP, Gossett J, Slikker W, Paule MG (1998): Acute effects of dexfenfluramine (d-FEN) and methylenedioxymethamphetamine (MDMA) before and after short-course, high-dose treatment. Ann N Y Acad Sci 844:183-190

Frederick DL, Ali SF, Slikker W, Gillam MP, Allen RR, Paule MG (1995): Behavioral and neurochemical effects of chronic methylenedioxymethamphetamine (MDMA) treatment in rhesus monkeys. Neurotoxicol Teratol 17:531-543

Gamma A, Frei E, Lehmann D, Pascual-Marqui RD, Hell D, Vollenweider FX (2000): Mood state and brain electric activity in ecstasy users. Neuroreport 11:157-162

Hatzidimitriou G, McCann UD, Ricaurte GA (1999): Altered serotonin innervation patterns in the forebrain of monkeys treated with (+/-)3,4-methylenedioxymethamphetamine seven years previously: factors influencing abnormal recovery. J Neurosci 19:5096-5107

Insel TR, Battaglia G, Johannessen JN, Marra S, De Souza EB (1989): 3,4-Methylenedioxymethamphetamine ("ecstasy") selectively destroys brain serotonin terminals in rhesus monkeys. J Pharmacol Exp Ther 249:713-720

Krystal JH, Price LH, Opsahl C, Ricaurte GA, Heninger GR (1992): Chronic 3,4-methylenedioxymethamphetamine (MDMA) use: effects on mood and neuropsychological function? Am J Drug Alcohol Abuse 18:331-341

Li AA, Marek GJ, Vosmer G, Seiden LS (1989): Long-term central 5-HT depletions resulting from repeated administration of MDMA enhances the effects of single 
administration of MDMA on schedule-controlled behavior of rats. Pharmacol Biochem Behav 33:641-64;8

McCann UD, Ridenour A, Shaham Y, Ricaurte GA (1994): Serotonin neurotoxicity after (+/-)3,4-methylenedioxymethamphetamine (MDMA; "Ecstasy"): a controlled study in humans. Neuropsychopharmacology 10:129-138

McCann UD, Szabo Z, Scheffel U, Dannals RF, Ricaurte GA (1998): Positron emission tomographic evidence of toxic effect of MDMA ("Ecstasy") on brain serotonin neurons in human beings. Lancet 352:1433-1437

McKenna DJ, Peroutka SJ (1990): Neurochemistry and neurotoxicity of 3,4-methylenedioxymethamphetamine (MDMA, "ecstasy"). J Neurochem 54:14-22

Morgan MJ (1998): Recreational use of "ecstasy" (MDMA) is associated with elevated impulsivity. Neuropsychopharmacology 19:252-264

Morgan MJ (1999): Memory deficits associated with recreational use of "ecstasy" (MDMA). Psychopharmacology (Berl) 141:30-36

Obrocki J, Buchert R, Vaterlein O, Thomasius R, Beyer W, Schiemann T (1999): Ecstasy-long-term effects on the human central nervous system revealed by positron emission tomography. Br J Psychiatry 175:186-188

Park SB, Coull JT, McShane RH, Young AH, Sahakian BJ, Robbins TW, Cowen PJ (1994): Tryptophan depletion in normal volunteers produces selective impairments in learning and memory. Neuropharmacology 33:575-588

Parrott AC, Lasky J (1998): Ecstasy (MDMA) effects upon mood and cognition: before, during and after a Saturday night dance. Psychopharmacology (Berl) 139:261-268

Parrott AC, Lees A, Garnham NJ, Jones M, Wesnes K (1998): Cognitive performance in recreational users of MDMA of 'ecstasy': evidence for memory deficits. J Psychopharmacol 12:79-83

Peroutka SJ (1987): Incidence of recreational use of 3,4-methylenedimethoxymethamphetamine (MDMA, "ecstasy") on an undergraduate campus [letter]. N Engl J Med 317:1542-1543

Prospero-Garcia O, Gold LH, Fox HS, Polis I, Koob GF, Bloom FE, Henriksen SJ (1996): Microglia-passaged simian immunodeficiency virus induces neurophysiological abnormalities in monkeys. Proc Natl Acad Sci U S A 93:14158-14163

Ricaurte GA, DeLanney LE, Irwin I, Langston JW (1988a): Toxic effects of MDMA on central serotonergic neurons in the primate:importance of route and frequency of drug administration. Brain Res 446:165-168

Ricaurte GA, DeLanney LE, Wiener SG, Irwin I, Langston JW (1988b): 5-Hydroxyindoleacetic acid in cerebrospinal fluid reflects serotonergic damage induced by 3,4methylenedioxymethamphetamine in CNS of nonhuman primates. Brain Res 474:359-363

Ricaurte GA, Forno LS, Wilson MA, DeLanney LE, Irwin I, Molliver ME, Langston JW (1988c): (+/-)3,4-Methylene- dioxymethamphetamine selectively damages central serotonergic neurons in nonhuman primates. JAMA 260:51-55

Ricaurte GA, Martello AL, Katz JL, Martello MB (1992): Lasting effects of (+-)-3,4-methylenedioxymethamphetamine (MDMA) on central serotonergic neurons in nonhuman primates: neurochemical observations. J Pharmacol Exp Ther 261:616-622

Scheffel U, Szabo Z, Mathews WB, Finley PA, Dannals RF, Ravert HT, Szabo K, Yuan J, Ricaurte GA (1998): In vivo detection of short- and long-term MDMA neurotoxicity-a positron emission tomography study in the living baboon brain. Synapse 29:183-192

Schuster P, Lieb R, Lamertz C, Wittchen HU (1998): Is the use of ecstasy and hallucinogens increasing? Results from a community study. Eur Addict Res 4:75-82

Semple DM, Ebmeier KP, Glabus MF, O'Carroll RE, Johnstone EC (1999): Reduced in vivo binding to the serotonin transporter in the cerebral cortex of MDMA ('ecstasy') users. Br J Psychiatry 175:63-69

Steele TD, McCann UD, Ricaurte GA (1994): 3,4-Methylenedioxymethamphetamine (MDMA, "Ecstasy"): pharmacology and toxicology in animals and humans. Addiction 89:539-551

Taffe MA, Weed MR, Gold LH (1999): Scopolamine alters rhesus monkey performance on a novel neuropsychological testing battery. Cogn Brain Res 8:203-212

Thompson AM, Moore KR, Thompson GC (1995): Distribution and origin of serotoninergic afferents to guinea pig cochlear nucleus. J Comp Neurol 351:104-116

Thompson AM, Thompson GC (1995): Light microscopic evidence of serotoninergic projections to olivocochlear neurons in the bush baby (Otolemur garnettii). Brain Res 695:263-266

Thompson GC, Thompson AM (1986): Olivocochlear neurons in the squirrel monkey brainstem. J Comp Neurol 254:246-258

Thompson GC, Thompson AM, Garrett KM, Britton BH (1994): Serotonin and serotonin receptors in the central auditory system. Otolaryngol Head Neck Surg 110:93-102

Vollenweider FX, Gamma A, Liechti M, Huber T (1998): Psychological and cardiovascular effects and short-term sequelae of MDMA ("ecstasy") in MDMA-naive healthy volunteers. Neuropsychopharmacology 19:241-251

Weed MR, Gold LH (1998): The effects of dopaminergic agents on reaction time in rhesus monkeys. Psychopharmacology (Berl) 137:33-42

Weed MR, Taffe MA, Polis I, Roberts AC, Robbins TW, Koob GF, Bloom FE, Gold LH (1999): Performance norms for a rhesus monkey neuropsychological testing battery: Acquisition and long-term performance. Cogn Brain Res 8:184-201

Yeh SY (1999): N-tert-butyl-alpha-phenylnitrone protects against 3,4- methylenedioxymethamphetamine-induced depletion of serotonin in rats. Synapse 31:169-177 